\title{
EVOLUCIÓN JURÍDICA DE LA EMPRESA
}

Enrique Vigil Oliveros ${ }^{1}$

\section{RESUMEN}

El presente informe tiene como objetivo verificar el origen de la empresa. Existen diversos antecedentes históricos que describen el inicio de la empresa o las primeras transacciones que podrían ser catalogadas como empresa. Sin embargo, no hay uniformidad de los autores en establecer una posible data del inicio de la misma, al punto que inclusive podría señalarse épocas distintas de más de mil años de diferencia. Por ello, trataremos de verificar si algunas manifestaciones ocurridas en las grandes culturas antiguas podrían ser realmente catalogadas como empresa o simplemente serían considerados actos de comercio. Se hará una descripción histórica, jurídica y económica.

\section{ABSTRACT}

This paper aims to confirm the origin of companies. There are different kinds of historical sources that describe the beginning of companies or the first transactions that could be classified as an entrepreneurial venture. However, scholars cannot agree on a possible date for the beginning of companies. In fact, they propose dates that could vary for as much as over a thousand years. Therefore, we will try to determine if some events in the great ancient civilizations could really be classified as entrepreneurial or simply as commercial transactions. This subject is addressed from a historical, legal and financial approach.

\section{PALABRAS CLAVES}

Comercio, empresa, comerciante, empresario, mercados, ferias, empresa individual de responsabilidad limitada, sociedad, corporación.

\section{KEYWORDS}

Trade, Company, Trader, Entrepreneur, Markets, Fairs, Sole Trader, Proprietorship, Partnership, Corporation.

\section{ANTECEDENTES EdAD ANTIGUA}

En época antigua tenemos antecedentes en las grandes culturas como Fenicia, Grecia y Roma.

En Fenicia existen indicios de empresa, por cuanto fueron grandes comerciantes, se remonta al comercio marítimo, que realizaban con otras culturas como Grecia. Como señala el maestro Ulises Montoya Manfredi en su libro Derecho Comercial I, los fenicios comercializaban productos agrícolas, ganaderos e incluso algunos metales como bronce y cobre.
En el aspecto económico, el comercio era la actividad principal de la economía de los fenicios, esta consistía en el intercambio o trueque de mercancías que ellos mismos producían y el transporte de las elaboradas por otros pueblos. Fueron los grandes mercaderes de la antigüedad. La

1 Giurista d'Impresa por la Universita di Bologna-Italia. Director del Departamento Académico de Ciencias Juridicas de Unifé. Docente de los cursos de Sociedades I y II. 
geografía les brindaba los elementos básicos para construir barcos y organizar compañías de navegación.

En cuanto a los antecedentes jurídicos encontramos que el avance en las instituciones jurídicas es evidente, destacándose la Lex Rhodia y la echazón adoptadas por el derecho griego y romano.

En Grecia: "La actividad comercial no gozó de consideración en Grecia. Platón y Aristóteles reprobaron esta actividad al igual que todas las ocupaciones manuales, a las que solo podían dedicarse manos serviles. Sin embargo, el comercio tuvo gran desarrollo sobre todo en las numerosas colonias griegas, gracias a las Leyes de Solón y al establecimiento de un buen sistema de pesas y medidas"2.

Asimismo, en el aspecto económico las empresas financieras encuentran su origen más remoto en la cultura griega, iniciando sus actividades mediante el cambio de monedas $y$, posteriormente, otorgando préstamos con intereses o con garantía de prenda sobre tierras agrícolas, que el banquero explotaba hasta que el deudor cumplía con su obligación.

Sobre la Banca CARLOS VARGAS VASSEROT ${ }^{3}$ textualmente dice: "No se deben olvidar tampoco las importantes contribuciones de Grecia a la ordenación de la banca, con la existencia de normas peculiares que obligaban a los banqueros a llevar libros obligatorios, y la práctica habitual por parte de estos bancos de la llevanza de servicios de caja a sus clientes, de cambio de moneda, la documentación de órdenes de pago y la creación de títulos a la orden y al porteador (REHME, Historia universal del Derecho mercantil, cit., pp. 51 a 53). RIPERT y ROBLOT, Traité de Droit commercial, t. I, París, Ed. LGDJ, 17. ${ }^{a}$ ed., 1998, p. 10, citan la existencia contratos privados e informes de abogados (Isocrates y Deosthenes) que demuestran las prácticas bancarias griegas" 4 .

En cuanto al derecho positivo estuvo contenido en las leyes Rodias, que rigieron en todos los pueblos de Grecia y que más tarde fueron incorporadas al Digesto.

Sobre las Leyes de Solón "en los asuntos económicos destacan las leyes que han dado lugar a reformas como la seisachtheia, el fin de la esclavitud por deudas, amnistía y perdón a todos los deudores y limitación de la compra de tierras a los eupátridas que seguían haciendo negocio con la quiebra de los pequeños y medianos propietarios" 5 .

En el caso de Roma, citando a Aaron Oyarce Yuzzelli, quien realiza un análisis histórico y comparatístico de la empresa, cita a Feliciano Serrao en su libro de Diritto Pri- vato Economia e Societa nella Storia di Roma, nos señala la "teoría del esclavo manager" por la cual el origen de la empresa es la familia, teniendo como elementos la participación de dos o más personas, el dominus y el esclavo, fin de lucro, responsabilidad limitada.

Se podría señalar que existía empresa porque se concertaban los elementos para su constitución y funcionamiento, el esclavo aquí tenía la función de gerente y el dominus el propietario de la empresa.

Respecto a los antecedentes jurídicos, se puede decir que los romanos en ciertas actividades comerciales, adaptaron leyes de otros pueblos.

Es el caso, por ejemplo, de la Lex Rhodia de lactu, en el comercio marítimo. "Fenicios y griegos se rigieron por la costumbre en sus relaciones de comercio marítimo, estas se cristalizaron en la Lex Rhodia de lactu (que reglamentaba la echazón, reparto de las perdidas, ante un siniestro 0 percance, proporcionalmente entre los interesados), considerada originaria de la Isla de Rodas y que posteriormente fue reconocida en el Digesto como ley común del mar. Por su parte, el lus Civile aportó una serie de principios que enriquecieron la tradición del comercio marítimo"6.

"De las Leyes rodias tomaron los romanos, igualmente, las

\footnotetext{
MONTOYA MANFREDI Ulises. Derecho Comercial. Tomo I. 2004.

VARGAS VASSEROT Carlos. (2012). La evolución histórica del Derecho mercantil y su concepto.

VARGAS VASSEROT Carlos, La evolución histórica y el concepto del Derecho Mercantil. 2012.

SAENZ JIMENEZ Sergui. "Solón el legislador". 2013.

CRUZ BARNEY Oscar, Derecho Mercantil y Jurisdicción Mercantil: Una relación necesaria. El subrayado es nuestro.
} 
acciones exercitoria (actio exercitoria) e institoria (actio institoria) en virtud de ellas, el que ha contratado con el capitán de la nave, puede demandar al propietario por los actos del capitán o la responsabilidad de este o de quien lo sustituye, por reputarse que existe una relación de mandato o una autorización para sustitución de persona"”.

Fue a partir de la Roma Imperial y su dominio sobre toda la cuenca del Mediterráneo cuando se estructuraron los contratos de representación, las reglamentaciones marítimas, las instituciones bancarias y de cuentas como el receptum argentariorum, contrato en virtud del cual el banquero se comprometía a pagar las deudas de su cliente, es decir, una especie de aval bancario; o como el liber accepti et depensi, en el cual los romanos anotaban las sumas recibidas de sus clientes y las que ellos pagaban, esta contabilidad era muy elemental pero tenía valor probatorio en justicia, y de ella nació la obligatio litteris.

\section{Génesis de los mercados:}

"A lo largo de la historia has existido diferentes modos de organización, el comercio y los intercambios de mercancías y servicios. La reciprocidad (el intercambio) y la redistribución fueron mecanismos habituales en imperios antiguos.

La expansión agrícola permitió alimentar a un mayor número de personas y eso estimuló un proceso de especialización económica cuyo resultado más visible fue el desarrollo urbano.

El crecimiento del comercio y los intercambios, actividades llevadas a cabo por una clase cada vez más numerosa de comerciantes impulsó la generalización de la moneda y el crédito". ${ }^{8}$

$\mathrm{Si}$ nos remontamos al origen etimológico de empresa, la palabra deriva del término emprendedor, en ese sentido, podríamos establecer que si existió empresa en estas culturas.

\section{ANTECEDENTES EdAd MEDIA}

"En los países bajos e Inglaterra, desde el siglo XVII la actividad agrícola paso de ser entendida como una explotación según el ciclo natural (agricultura tradicional, que producía para la subsistencia) a ser concebida como una empresa (agricultura capitalista) que producía para el mercado" 9 .
"En la Edad Media existían en Europa dos grandes focos comerciales: El mar del Norte y el Mediterráneo; en el Mediterráneo estaba dominado por los italianos y en el mar del Norte por los flamencos del norte de Bélgica y por las ciudades hanseáticas. Se ponían en contacto por vía terrestre siguiendo los cursos de los ríos Ródano y Rin hasta que a principios del siglo XIV los italianos los pusieron en contacto por vía marítima a través del Estrecho de Gibraltar.

Para el desarrollo del comercio fueron fundamentales la creación de dos instituciones: los mercados y las ferias.

Los mercados tenían una periodicidad semanal o quincenal y en ellos se intercambiaban sobre todo productos de la comarca, por el contrario, las ferias solo se celebraban una o dos veces al año y se intercambiaban productos regionales, nacionales e internacionales" 10 .

"La precariedad de los sistemas de transporte y comunicaciones, la inseguridad en las rutas, tanto terrestres como marítimas y el escaso desarrollo de los mercados infundían a la actividad comercial, especialmente en la realizada a media y larga distancia, un

7 MONTOYA MANFREDI Ulises. Derecho Comercial. Tomo I. 2004. Pág. 68-69. Comparar también EMILIO VALIÑO, “Las Actiones Adiecticiae Quialitatis y sus relaciones". Para mayor entendimiento: El institor podía ser hombre o mujer, libre o esclavo, tanto del principal como ajeno; en tanto originariamente es siempre un sometido del principal, en la segunda época puede serlo también un extraño no sometido a su potestad. Cuando el institor, en el desarrollo de su actividad mercantil, celebra negocios jurídicos asumiendo obligaciones respecto a terceros, los acreedores tienen la facultad de elegir o bien demandar ex negotio al praepositus (si no era esclavo) o bien al principal con la acción adyecticia. La responsabilidad del principal solo tiene lugar si el factor ha actuado en el ámbito de la condicio praepositionis, es decir, dentro de los límites de su apoderamiento: si estos son traspasados, no hay responsabilidad del principal.

8 VALDALISO, Jesús María. LÓPEZ, Santiago. “Historia Económica de la Empresa”. Madrid: Editorial Critica SL. 2007.

9 VALDALISO, Jesús María. LÓPEZ, Santiago. “Historia Económica de la Empresa”. Madrid: Editorial Critica SL. 2007.

10 Idem. 
componente de riesgo y aventura nada desdeñables.

Es por ello que las ferias y mercados recibían la protección política de príncipes a cambio de un impuesto sobre los ingresos (coste de protección) y en ellas se desarrollaron instituciones que favorecieron el comercio.

El comerciante individual era el tipo de empresa más extendido en Europa, el norte de Africa y el Oriente hasta el siglo XIII."11

Tanto las ferias como los mercados necesitaban para que pudieran desarrollarse, la protección legal de los reyes o de los señores feudales.

"El comercio se reducía al trueque y a las transacciones en ferias y mercados. Las empresas o talleres comarcales. Las empresas o talleres manufactureros raramente sobrepasaban el carácter familiar. Dado el escaso peso del mercado, la división del trabajo era mínima: las villas y las ciudades, los sectores comercial, manufacturero y de servicios, se reducían a islotes en medio de un mundo rural."12

Se inicia con el tránsito entre el sistema económico romano basado en la municipalidad de la civitas, con el sistema latifundista que tendrá influencia romano germánica hasta culminar en el feudalismo.

No existen grandes vestigios de empresa en Europa, por cuanto existía las Monarquías
Absolutas que derivaban en un sistema feudal, en el cual el Señor Feudal era el amo de las tierras o comarcas, conocidas como feudos, en ellas laboraban los vasallos conocidos como feudatarios a cambio de alimentación, vestido, vivienda y protección. Se puede establecer que esta etapa predominaba el comercio artesanal y agrícola. Sin embargo, cuando se produce el cisma de la Iglesia Católica por la toma de Jerusalén a manos de los turcos, se organizan las cruzadas y ello trajo como consecuencia que Europa desplace grandes ejércitos al mando de los emperadores y por ello los feudos fueron tomados y producen la diáspora de los campesinos y artesanos que se desplazan por Europa ofreciendo sus productos y ello trajo dos fenómenos las ferias y luego los mercados.

Desde el punto de vista económico, la Edad Media se caracterizó por:

a) Estancamiento en los primeros cinco siglos.

b) La institución de los Consejos, los gremios, las ferias y los mercados, así como la influencia del cristianismo, lograron reactivar el comercio entre las empresas.

c) Dificultades y peligros constantes para el comercio por la piratería y el pillaje.

d) El enclaustramiento de la vida económica dentro de la villa o feudo.

e) Se creó la institución del mercado como institución pública para realizar transacciones comerciales. f) En el siglo $X I$ se dio gran impulso al comercio y al a industria por lo que se afirmó el establecimiento de los gremios comerciales, mediante la creación de la institución de los cónsules (Juzgadores) y, más tarde, los estatutos de las organizaciones comerciales.

Los Centros de Comercio corresponden a los grandes negocios entre regiones, dando origen al surgimiento de grandes centros de productores y de exportadores, en los que se desarrolló el comercio internacional, donde la costumbre es la norma, el consensualismo absoluto es la regla y el individualismo la técnica jurídica.

Las ferias, en un principio de carácter religioso, se convierten en ocasiones para intercambio de mercaderías y de dinero de comerciantes que arribaban con el propósito de efectuar sus transacciones, beneficiándose con los derechos de mercado, así como de instituciones como la "paz de Dios" o la "tregua de Dios", mediante la cual el Rey o el Señor que patrocinaba la feria garantizaba la paz dentro de la misma y en las vías de acceso, lo que les permitía desplazamiento seguro a los comerciantes.

La forma más antigua de sociedad es la llamada societas maris o commenda que aparece en Italia en el siglo $X$, esta sociedad es un contrato entre un socio capitalista sedentario y un comerciante o capitán de un barco que realiza el viaje y

12 SUÁREZ VALDÉS, Joaquín Ocampo. “Historia económica mundial y de España”. España: Universidad de Oviedo. 2006. 
aporta el trabajo, ambas partes se reparten los beneficios o las perdidas según una fórmula acordada y la sociedad dura solo un viaje, siendo por tanto una sociedad muy sencilla que dura hasta el siglo XVII por toda Europa.

Los comerciantes, como los banqueros y artesanos, se agrupan en distintas organizaciones de las cuales se pueden distinguir dos tipos básicos: las corporaciones mercantiles, en las que los grandes comerciantes se asocian, y los gremios locales (corporaciones menores), que responden a las necesidades del modesto comercio local.

En cuanto a los antecedentes jurídicos, la necesidad de que las transacciones comerciales de las pequeñas y grandes empresas fueran reguladas por normas especiales, dio origen a los siguientes cuerpos normativos.

El derecho positivo de esta etapa, está formada básicamente por los Estatutos Locales.

Los Estatutos eran una mezcla de los usos y prácticas comerciales de aceptación general. Los Estatutos hacían el oficio de ley y jurisprudencia. Los Estatutos Locales se aplicaban en determinadas ciudades, los más notables son los de Venecia, Genova, Florencia y Marsella.

\section{ANTECEDENTES ÉPOCA MODERNA}

En el plano político - social, es un hecho es que a partir del siglo XVI los Estados fueron dirigiéndose lentamente a lo que será llamado el Ancien
Régime, caracterizado por la decadencia de las grandes fuerzas que en la Edad Media habían representado el poder: el feudalismo, las autoridades municipales y las corporaciones mercantiles. Frente a todos ellos se hallaba el Príncipe con su corte y su burocracia, un poder central que estaba articulándose de modo cada vez más eficaz y que alcanzará durante el siglo XVII la forma extrema del Estado absoluto con la identificación del Estado y el Monarca a través del concepto de soberanía.

Durante los siglos XVII y XVIII, se instauró el Mercantilismo propiamente dicho, el cual tenía su razón de ser en el comercio como actividad económica básica. En este contexto surgió la empresa comercial, que se dedicaba a desarrollar el comercio internacional. En esta época se desarrolló fuertemente la actividad bancaria, que se basaba principalmente en financiar las guerras de las mayores potencias de la época.

Los descubrimientos geográficos trajeron como consecuencia un intercambio de bienes entre las metrópolis y sus colonias, si bien es cierto ello no puede ser considerado un comercio por cuanto no había finalidad lucrativa, solo intercambios, en el virreinato si se permitió en el caso de los españoles peninsulares, criollos y mestizos el comercio, podríamos aquí señalar que existía empresa, pero aun de manera artesanal.

Desde el punto de vista económico, se abren nuevas y más amplias rutas para el comercio marítimo. El descubrimiento de América originó la expansión colonial, y, la explotación de los recursos del Nuevo Continente provocó una gran afluencia de metales preciosos hacia Europa.

En la Edad Moderna se produjo un claro progreso comercial, manufacturero y crediticio, y se inicia un proceso de industrialización. Se crean los primeros bancos europeos, como el de San Jorge en Milán, San Ambrosio en Florencia y las Bolsas en Flandes.

En cuanto a los antecedentes jurídicos, a partir del siglo $\mathrm{XV}$ renace el comercio con las rutas abiertas a la navegación y se empieza a regular normativamente la actividad empresarial.

Francia da un paso definitivo durante el siglo XVII a una nueva etapa legislativa con las Ordenanzas del Comercio (1673) y la Marina (1681). Estas regulan el comercio terrestre y marítimo, y son colecciones de disposiciones legales y costumbres de distinta procedencia y época, intentado más que innovar, transcribir el Derecho existente con normas claras, precisas y adaptadas a un sistema, con el que lograr una mayor certeza y facilitar su aplicación a los ciudadanos.

En Alemania hubo una gran profusión de Estatutos, Ordenanzas, Reglamentos y compilaciones particulares, entre éstas últimas destacan las Ordenanzas marítimas de la Hansa teutónica (1591), y se dictaron algunas codificaciones en Prusia, como fue el Allgemeins Landrecht für preussischen Staaten (1794), que hay 
quién la considera la primera codificación moderna, y que contiene una ordenación del Derecho privado prusiano, con numerosas normas que regulan las actividades comerciales de las empresas.

En Inglaterra encontramos las primeras iniciativas para la tutela de las invenciones industriales (Estatuto de los monopolios de 1623) y para la exclusiva del reconocimiento del derecho de autor se promulgó el Estatuto de la Reina Ana (1710), esta normativa fue enfocada a corregir los problemas existentes en ese momento en torno a la reproducción y venta de obras literarias. La misma le reconoce al autor su derecho de propiedad. Lo que se pretendía brindarle al autor el reconocimiento como titular de su obra y por consiguiente de los derechos que de ella derivan.

“Endemann (en 1875) y Pisko (en 1918) fueron los primeros autores que se fijaron en la empresa, como concepto importante en el derecho del comercio."13

\section{ANTECEDENTES ÉPOCA CONTEMPORÁNEA}

Luego de la Revolución Francesa, lo que provoca que las estructuras del Antiguo Régimen sean abolidas para instituir un sistema más racional, basado en la Ley y el reconocimiento al individuo de ciertos derechos y libertades inviolables, en el Imperio de Napoleón Bonaparte se promulga el primer Código de Comercio en el año 1807 donde se recoge las transacciones con finalidad lucrativa. Sin embargo, muchos autores coinciden que la empresa nace con la producción en serie, y ello se realizó en la Revolución Industrial. Desde allí el auge de la empresa se realiza a gran escala, hasta que después de las guerras mundiales se desarrolla en gran escala la industria del automovilismo y del armamentismo.

En ese sentido, el Código francés de 1807 entendía a la empresa como "un acto de comercio", hecho que era resultado directo de la intención de dar apariencia de hecho objetivo a la actividad del comerciante y correspondía, por lo tanto, a la aplicación de la teoría del acto de comercio que en la actualidad ya ha sido descartada en casi todas sus manifestaciones.

En la década de los sesentas del siglo pasado, se inicia la era cibernética y con ella la revolución en el comercio por cuanto con la negociación en línea las comercializaciones aumentan a través de los contratos entre ausentes.

Desde el punto de vista económico, el liberalismo, con su gran teórico ADAM SMITH, considera la libertad uno de los presupuestos fundamentales del progreso y bienestar social y se postula la libertad de mercado. Existe una confianza ciega en las ventajas de la competencia como motor del crecimiento económico y del progreso técnico (que guía con mano invisible los recursos). El Estado no interviene en la economía, adoptando una postura neutral frente a ésta que, a través de su pieza básica (el mercado), se autorregula. Corresponde, por tanto, al Estado tan sólo asegurar legislativamente que tal autorregulación se produzca (Estado policía).

En cuanto a los antecedentes jurídicos, en 1804 se promulgó el Código civil francés, que recogerá un Derecho histórico pues su contenido se estructura, fundamentalmente, sobre la base del Derecho romano y, posteriormente, se promulgará el Código de comercio en 1807, fuertemente influido por las Ordenanzas francesas del Comercio y la Marina de Colbert, lo que será determinante a la hora de delimitar el concepto de Derecho mercantil recogido en dicho Código. En España, el Código de comercio de 1829 constituye una obra legislativa de extraordinario valor para su época, constituyendo cronológicamente el segundo Código de comercio del mundo, después del napoleónico de 1807.

En Perú, en el año 1959 se promulgó la Ley $N^{\circ} 13270$, Ley de Promoción industrial, a la que podemos calificar como una de las primeras expresiones del Derecho Empresarial Peruano, porque define a la "empresa industrial" y regula el marco jurídico de su actuación. Su artículo 30 prescribe:

"Se denomina 'empresa industrial' o simplemente 'empresa', a la persona natural o jurídica que ejerce una determinada actividad económica que, por su finalidad, está am-

13 ABASCAL ZAMORA, José María. “Empresa, Empresario y Negociación Mercantil”. En: http://www.juridicas. unam.mx/publica/librev/rev/jurid/cont/4/pr/pr1.pdf 
parada por esta Ley de Promoción Industrial, con la amplitud o con las limitaciones que ella determina".

La Constitución Política del Perú de 1979 en su artículo 130 señala lo siguiente:

Las empresas, cualquiera sea su modalidad, son unidades de producción cuya eficiencia y contribución al bien común son exigibles por el Estado de acuerdo con la ley.

"La empresa (entendida como la organización económica dedicada a la producción o comercialización de bienes o a la prestación de servicios) puede estructurarse adoptando un modelo individual o un modelo colectivo y en cada caso variarán las modalidades empresariales dependiendo de la legislación en que se enmarque" 14 .

\section{NATURALEZA JURÍDICA DE LA EMPRESA}

Alfred Chandlre define a la empresa como una entidad legal -que supone firmar contratos con proveedores, distribuidores, empleados y con frecuencia con los clientes. También es una entidad administrativa, ya que dentro de ella existen una división del trabajo, o bien porque saca adelante más de una actividad individual y se necesita un equipo de gerentes para coordinar y monitorear estas actividades diversas. hasta aquí Chandler ha identificado una naturaleza legal -que es una esencia contractual, verbal o escrita, entre diferentes par- tes- y una naturaleza administrativa, referida al trabajo y al modo como se realiza.

El objeto de nuestro estudio, es analizar el aspecto jurídico de la empresa, debido a ello abordaremos la naturaleza jurídica de la empresa.

\section{"La empresa como sujeto de derecho.}

Una de las teorías propuestas para explicar la naturaleza jurídica de la empresa la identificaba con las personas jurídica y sostenía que la empresa no era un simple conjunto de medios de producción inertes sino que la fusión de ciertos elementos había producido su independencia jurídica y el nacimiento de una nueva persona.

Fernández Sessarego concibe a la empresa como una "organización de personas" en la cual confluyen múltiples intereses. de esta manera, además del titular de los bienes y derechos que utiliza la empresa en su actividad económica, existen otros agentes actuantes que tienen interés en ella, como los trabajadores. Concluye este autor señalando que “... resultan hitos históricos el definir a la empresa como la actividad del comerciante o confundirla con el patrimonio que maneja, para terminar, afirmando que la empresa es un "objeto". Es decir, convirtiendo en "objeto" a una pluralidad de seres humanos actuantes en la empresa”. (1990, 349).

La concepción de la empresa como sujeto de derecho difie- re en gran medida de las posturas iniciales que otorgaban personalidad jurídica a la empresa.

\section{La empresa como objeto de derecho.}

Los intentos por capturar la esencia de la empresa para el derecho han pasado por la elaboración de varias teorías que la conciben como un objeto unitario que forma parte de un patrimonio de su titular. Estas teorías, no reconocen en la empresa una organización de personas, sino más bien una organización de bienes y derechos utilizados para realizar la actividad empresarial. La concepción de la empresa como un objeto se fundamenta en la posibilidad de constituirla en materia de tráfico jurídico.

Nuestra legislación, al referirse a la empresa puede considerarla como un sujeto de derechos y obligaciones, y, en otros casos, como un objeto de derecho. Esto último se aprecia en diversas disposiciones del Código Civil de 1984 que se refieren a la empresa como un objeto complejo susceptible de ser heredado, de ser dado en hipoteca, de ser adjudicado en el caso de una división de bienes como consecuencia del fenecimiento de la sociedad de gananciales o de ser considerado como parte de la sociedad de gananciales."15

"Concepto jurídico de empresa según la doctrina alemana.

Según el jurista alemán Karsten Schmidt, no existe un concep-

14 DANIEL ECHAIZ, “Manual Societario”, Segunda Edicion. Lima. 2012.

15 GALVAN PAREJA, Gustavo. "Apuntes sobre el uso del término Empresa en la doctrina y legislación peruana". En: http://sisbib.unmsm.edu.pe/bibvirtualdata/publicaciones/economia/ 5/a08.pdf 
to jurídico general de empresa. Lo que existe son diversos ámbitos jurídicos que tratan de desarrollar el concepto de empresa, cada uno desde su propia perspectiva, pero al decir de este autor, el concepto de empresa desarrollado por otras ramas del derecho debe ser analizado con detenci6n y juicio crítico y no ser asumido de buenas a primeras por el derecho comercial. Asimismo, este autor sostiene que, si tratamos de asimilar el concepto de empresa y empresario a las categorías tradicionales del derecho comercial, el concepto de comerciante corresponde al concepto de titular de empresa o empresario y el concepto de actividad comercial con el concepto de empresa.

Por su parte, el jurista alemán Raisch define al empresario como "quien en forma independiente y mediante una unidad económica organizada, establecida en forma duradera, ofrece prestaciones con valor económico a otros participantes del mercado". Empresa, por consiguiente, según este último autor, es la unidad económica organizada mediante la cual el empresario actúa en el mercado. Raisch señala que toda empresa tiene ciertas características esenciales:

1. Un mínimo de medios materiales y personales, los que varían caso a caso (ejemplo, una gran empresa eléctrica en comparación con un sencillo corredor de propiedades).
2. Una mínima medida de organización unitaria. El grado de organización varía caso a caso y evoluciona, pero siempre se trata de una unidad organizada.

3. Una mínima presencia en el mercado. La empresa se convierte en el punto de contacto de relaciones jurídicas.

Por su parte, el jurista Julius von Gierke señala que "empresa, en sentido estricto, es el ámbito de actuación conformado por la actividad económica, los bienes y derechos regularmente incorporados, y adquiridos, incluyendo las deudas que le corresponden".

Es decir, Von Gierke se inclina por un concepto de empresa como actividad". ${ }^{16}$

\section{DIFERENCIA ENTRE EMPRESA, EMPRESARIO $Y$ COMERCIANTE.}

La palabra "empresa", de origen italiano, desde siempre ha evocado la idea de emprender una acción con ciertos objetivos; en su uso hay muchas veces un dejo de admiración por alguien que emprende o inicia una empresa, en términos de intentar lograr algo con esfuerzo. Esta idea desde las revoluciones industriales europeas acompañaría los esfuerzos del capital por diseñar procesos productivos que permitirían contar con nuevas formas de organización del trabajo, conservaría aquella cierta dosis de subjetividad admirativa, en términos de los retos que implican los esfuerzos por lograr los objetivos buscados. ${ }^{17}$

El derecho, por su parte, iría incorporando la idea de empresa de muy variadas formas, en atención sobre todo a las maneras como este ente participaba y actuaba en la vida social, política y económica de las naciones. Seria, así como se dotaría a la empresa de un cada vez más amplio y complejo marco jurídico, desde su nacimiento y existencia legal en áreas importantes del derecho privado, hasta ampliar su regulación en terrenos propios del derecho público.

Al respecto, Ferrara sostiene que Empresa se refiere a la actividad económica organizada, y el Empresario es el sujeto que ejerce dicha organización. ${ }^{18}$ Para la Empresa, el autor italiano, hace los siguientes distingos: Debe ser una actividad dirigida a la producción o cambio de bienes y servicios, una actividad lícita y que sea organizada y se desarrolle profesionalmente. Por esta última característica, se refiere a un sentido amplio de profesionalidad, se refiere a la mentalidad empresarial, el desarrollar y permanecer con la actividad empresarial. Por otro lado, Empresario es quien ejerce la actividad y se vale de la organización de las personas y bienes que implican.

Una de las mayores dificultades que encontramos en la determinación de nuestro con-

\footnotetext{
16 ARTEAGA ECHEVARRIA, Ignacio. “En busca del concepto jurídico de empresa”. En: https://repositorio.uc.cl/ bitstream/handle/11534/14931/000348272.pdf?sequence=1

17 REYNOSO CASTILLO, Carlos. "Las transformaciones del concepto de Empresa". México: Revista Latinoamericana de Derecho Social. En: http://www.revistas.unam.mx/ index.php/rlds/article/ viewFile/46160/41293

18 Visto en: http://www.juridicas.unam.mx/publica/librev/rev/jurid/cont/4/pr/pr1.pdf
} 
cepto, estriba en la diversidad de significados que se le dan al termino en cuestión. En la doctrina, en la ley y en el lenguaje vulgar, se le atribuyen los más diversos significados: se habla de empresa como organismo económico, como comunidad de trabajo, como actividad económica organizada; se le confunde con el conjunto instrumental que sirve al empresario para el desarrollo de su actividad; y, por último, se le llega a confundir con las personas jurídicas.

Para Shane ${ }^{19}$ : "la función empresarial implica el descubrimiento, evaluación y explotación de oportunidades de negocio que surgen en la economía. Los empresarios son los individuos que bien por sus propiedades cognitivas, bien por la posesión de información, descubren esas oportunidades.

El empresario tiene unos rasgos, funciones y un comportamiento: descubren crean y explotan oportunidades, afrontan el riesgo y la incertidumbre, promueven innovaciones y lideran cambios."

El concepto de empresario ha sufrido grandes modificaciones desde la época del capitalismo mercantilista hasta la actualidad. de ser el propietario de la empresa y el que tomaba las decisiones, ha pasado a constituirse en una figura mucho más compleja, que no necesariamente tiene que ser una persona física ni el dueño de la empresa.
- SIGLO XIX.- Diversos propietarios financian conjuntamente la empresa. con la llegada de esta forma societaria se empiezan a separar por primera vez los objetivos del empresario y del capitalista. El capitalismo llega a una etapa en la cual el capital se fracciona entre un número amplio de accionistas y se elige al empresario en función de su capacidad. este nuevo empresario afronta ahora un riesgo más profesional que patrimonial. Sus funciones son organizar, planificar y dirigir.

- SIGLO XX.- El empresario es la persona que asume el riesgo derivado de la actividad económica, ya que adelanta una cantidad de dinero real y cierta con el objetivo de recoger un beneficio incierto. Las fases del cambio tecnológico eran tres: invención, innovación e imitación. El empresario era la figura que inventaba e innovaba en el mercado. La separación entre la propiedad y el control de la empresa que ya hemos visto trae consigo que el tamaño de muchas organizaciones y la complejidad de las decisiones que en ellas hay que tomar sea tal que muchas empresas no puedan ser dirigidas por una sola persona, sino por un órgano colegiado que se puede denominar tecnoestructura.

\section{PERÍODO PREHISPÁNICO DEL PERÚ Y LA EMPRESA}

Para realizar el estudio de la evolución del termino empre- sa en la historia del Perú, se debe de realizar un análisis de los acontecimientos económicos más relevantes que surgieron a través de esos años, ya que la denominación empresa que se traduce en unidad de organización dedicada a actividades industriales, mercantiles o de prestación de servicios con fines lucrativos, tiene un contexto económico que no se puede pasar por alto.

En los inicios de este periodo, los hombres fueron interactuando con la naturaleza, domesticando a plantas y animales, este acontecimiento es conocido por la arqueología como "la revolución neolítica”, así con el tiempo, se logra consolidar la agricultura y la ganadería, como una de las actividades de mayor producción, aparece la cerámica y las organizaciones estatales, como es el caso de Chavín, por ejemplo.

Se inició la tarea de fijar reglas de reconocimiento de los derechos de las personas sobre aquellos medios de vida que dependían de una cantidad de trabajo invertido en ellos. En ese sentido se reconoce a la propiedad como el conjunto de reglas de relación entre personas, que consiste en reconocer como propio, lo que nace del trabajo de cada cual, dado que la obtención de alimentos, tanto en calidad como en volumen, dependía de la calidad y cantidad de la fuerza de trabajo disponible. En este periodo se distinguía por haber desarrollado un sistema agropecuario para pro-

19 Mencionado por VALDALISO, Jesús María. LÓPEZ, Santiago." Historia Económica de la Empresa”. Madrid: Editorial Critica SL. 2007. 
ducir bienes de prestigio, por haber impulsado una metalurgia de tendencia ornamental. En la región alto andina el trueque era el sistema general de acceso a recursos de subsistencia, cabe precisar que, actividades tales como el transporte y el almacenamiento también formaban parte de la economía prehispánica.

En los años 200 a.c. se distinguieron como los logros generales, el predominio de sistemas agrícolas de riego, el crecimiento de asentamientos urbanos y el desarrollo de la producción artesanal esencialmente la cerámica, la textilería y la metalurgia- la población común asentada en la sierra se organizó en pequeñas aldeas. En contraposición, la costa norte y central, además de la organización de la población rural en aldeas, se construyeron conglomerados urbano-religiosos.

En la época del Tahuantinsuyo es preciso señalar que: "se trataba de una economía donde los precios en moneda acuñada en metales preciosos no existían. Estrictamente, tampoco se puede hablar de "capital", "salario", "renta" y "ahorro" con mucha frecuencia; y de usarlos, hay que hacerlo en un sentido distinto al de los economistas modernos, por tener implicaciones no aplicables a las situaciones de la vida antigua en los Andes, ya que se trató de una sociedad precapitalista.

(...) La organización económica del Tahuantinsuyo puede ser analizada convenientemente a partir de cuatro encabezados: $1^{\circ}$ la estructura de la propiedad y posesión de la tierra; $2^{\circ}$ la organización del trabajo; $3^{\circ}$ lo concerniente a la producción, distribución, intercambio y consumo; y $4^{\circ}$ las cuentas y medidas de valor."20

Sobre la propiedad se puede decir que se distinguían distintos tipos de pertenencia: de bienes inmuebles (tierra, casas, caminos, puentes, pozos, árboles); de objetos domésticos (como herramientas de trabajo y armas, que difieren según el sexo y la edad y que, por lo común, son heredados de acuerdo a la consanguinidad); de cosas almacenadas y acorraladas (alimentos, ganado); derechos sobre el uso económico (usufructo de los predios ocupados por los ayllus); derecho de los poderosos sobre personas y servicios humanos (yanas, mitayos, piñas); $y$, otras modalidades de dominio, como derechos exclusivos sobre canciones, danzas, hechizos y artesanías concretas.

Sobre la organización del trabajo, en el Tahuantinsuyo se distinguían la mita minka y ayni, ya que, "el trabajo se dividía según la participación de los campesinos y de los artesanos especialistas. Esta división era indispensable para el funcionamiento del sistema económico en su totalidad. Por lo tanto, en el Incario el trabajo se apuntalaba en tres pilares claves: la edad, el sexo y el rango social. Así, exis- tían labores únicamente para personas jóvenes y otras para adultas, las mismas que resultaban imposibles de ser ejecutadas por niños y ancianos. Otras ocupaciones estaban en manos exclusivas de determinadas clases sociales superiores, en contradicción a las labores a cargo de la nobleza de segundo y tercer orden y de los runas comunes." 21

Respecto a las actividades productivas, "buscaban auto proporcionarse provisiones para la subsistencia; bienes para regalar a sus familiares; bienes para satisfacer otras obligaciones, como por ejemplo, obsequios a los superiores y a los padres de la futura esposa; ofrendas a los ancestros, espíritus y divinidades; intercambiar con productos vegetales, animales y minerales de otras ecologías cercanas y lejanas; reservar semillas para la próxima siembra; y, finalmente depositaban las demasías, para situaciones de emergencia, en almacenes. En los pueblos ganaderos, los camélidos tenían diversas aplicaciones: por su pelambre; como sacrifico a seres sobrenaturales; como bestias de carga y, a veces, de transporte de niños, mujeres e inválidos; por su estiércol, que es un buen abono en las alturas; por sus huesos, que los convertían en herramientas para tejer y en instrumentos musicales; por su carne para la alimentación; por sus pieles que eran utilizadas como pellejos para alfombrar el piso y acondicionarlos como colchonetas para dormir y como cor-

\footnotetext{
20 Compendio de historia económica del Perú I: Economía prehispánica /Carlos Contreras, ed.; Luis Guillermo Lumbreras, Peter Kaulicke, Julián I. Santillana y Waldemar Espinoza Soriano. Lima: BCRP; IEP, 2008. (Serie: Historia Económica, 1).

21 Idem.
} 
tinas para tapar sus puertas; como recompensa por la futura esposa; y, como reparaciones de ofensas.

Es posible que parte de sus bienes almacenados, en situación de sobrantes, fuesen prestados a los parientes y amigos en ocasiones de emergencia, lo que sucedía con frecuencia. Por ejemplo, se podían prestar herramientas, balsas de pesca, adornos y trajes para danzas y hasta productos alimenticios. Hay pruebas documentales de que las devoluciones podían hacerlas con una adehala -agregado o interés-, aunque esto no debió funcionar siempre así, bien que debió tener cierta importancia". ${ }^{22}$

Se puede determinar que, en el Perú, no existió empresa ni comercio sino hasta la llegada de los españoles.

\section{LA EMPRESA INDIVIDUAL DE RESPONSABILIDAD LIMITADA EN EL PERÚ.}

En la década de los años setenta del siglo $X X$, en nuestro país se trató de realizar una distinción entre el comerciante y la persona natural que por sí sola, sin asociarse con otra, iniciaba una actividad económica creando una nueva persona jurídica, ello con el objeto de limitar su responsabilidad. Es por ello, que mediante Decreto Ley $\mathrm{N}^{\circ} 21621$ se regula este tipo de actividad.

"La Empresa Individual de Responsabilidad Limitada apa- rece en nuestra legislación con el Decreto-Ley $N^{\circ} 21621$ del 14 de Setiembre de 1976 con el propósito de crear una persona jurídica a través de la cual el comerciante individual, persona natural, pudiera tener la responsabilidad limitada que podían alcanzar las personas jurídicas mediante algunas de las formas societarias mercantiles.

La Empresa Individual de Responsabilidad Limitada no es más que una persona jurídica que por virtud de la ley tiene un patrimonio propio constituido por el aporte del titular y este patrimonio sirve para formar una unidad productiva o «empresa» de propiedad de la Empresa Individual de Responsabilidad Limitada.

Para quienes sostienen que la empresa es un sujeto de derecho, la Empresa Individual de Responsabilidad Limitada no es tampoco una empresa puesto que «No puede confundirse el caso de la empresa, que siempre está constituida por una organización de personas, que cuenta con un solo propietario de su patrimonio, con el del empresario individual que no requiere de una organización plural de personas para ejercer su actividad mercantil o artesanal.» (Fernández, 1986b, 63). Por este motivo, se ha planteado la utilización de otras denominaciones para esta persona jurídica tales como «empresario individual de responsabilidad limitada» (Fernández,1986a, 153)."23

\section{CONCEPTO JURÍDICO \\ DE EMPRESA EN PERÚ \\ UNA VISIÓN HACIA EL FUTURO}

El presente informe tiene como objetivo verificar si el término empresa tendrá que ser superado por las nuevas formas de comercio que se dan a través de la tecnología y las nuevas tendencias que consideran a la empresa como una unidad económica que se desarrolla de manera integrada, debido a la conjunción de varias disciplinas como el Derecho, la Economía, la Sociología entre otras.

Es importante, establecer que en los tiempos actuales, la empresa no tiene un carácter jerárquico, como lo establecía Frederick Winslow Taylor (Frederick Winslow Taylor y Henry Fayol, 2005), donde el Jefe era el que decidía los destinos del negocio, sino en la actualidad, como señala Richard Sennett(Richard Sennett -Traducción Daniel Najmías, 1998): la búsqueda de la flexibilidad y la adaptación a los nuevos mercados, modifica el espacio y los contratos laborales a corto plazo. Las empresas han pasado de una estructura jerárquica a una red, lo que provoca que los lazos sociales tarden más en desarrollarse y se debilite el trabajo en equipo con consecuencias a nivel personal, ya que no se crean lazos de lealtad y confianza.

Continuando con el análisis de Sennett, para ver el futuro de

22 GONZÁLEZ HOLGUíN, Diego 1951[1608] Vocabulario de la lengua general de todo el Pirv llamada lengua quichua. Lima: Imprenta Santa María.

23 GALVAN PAREJA, Gustavo. "Apuntes sobre el uso del término Empresa en la doctrina y legislación peruana”. En: http://sisbib.unmsm.edu.pe/bibvirtualdata/publicaciones/ economia/ 5/a08.pdf 
la empresa, desde su visión sociológica, en su otro libro (Hernando, 2006).

Establece que el mundo globalizado, existen tres principales desafíos a superar en los nuevos escenarios del capitalismo, caracterizados por la inestabilidad y fragmentariedad: la rápida adaptación a los cambios (sociales, laborales, etc.); el desarrollo de nuevas habilidades; y la renuncia al pasado como garantía de permanencia en las instituciones, especialmente empresariales. Estos tres rasgos que propone Sennett como claves para prosperar socialmente remiten a su juicio a tres grandes temas en torno los que gira la sociedad moderna: trabajo, talento y consumo.

Por su parte, (Luc Boltanski y Eve Chiapello Traducción MARISA PÉREZ COLINA / ALBERTO RIESCO SANZ / RAUUL SÁNCHEZ CEDILLO, 2010). Analizan al capitalismo desde las perspectivas del entorno político después de la revolución moderna industrial, superado el sistema jerárquico de las empresas. Señalan que el eje central de las empresas para obtener más ganancias no estriban en la lucha por la competencia con otras empresas, no se trata de recuperar el espacio perdido para lograr un rendimiento económico, sino todo lo contrario la se busca nuevas formas de hacer negocios, penetrar nuevos mercados quizás con los mismos productos o con otros productos o servicios. Esa es la nueva competencia de tipo global y no localizada como en épocas anteriores.

Estas ideas, nos dan un alcance de la verdadera dimensión de la empresa en la actualidad, como señalan los expertos, el gran avance que ha obtenido la empresa después de la postguerra y en el inicio de la era cibernética, trae como consecuencia una concepción multidisciplinaria de la misma, por ello, es importante incorporar a la noción jurídica las concepciones sociológicas, puesto que podríamos afirmar que ya desde los tiempos de Adam Smith, teniamos una concepción jurídico - económica. No, es que esta inclusión es nueva, por el contrario desde Carl Marx al hablar del capitalismo ya se entendía la nocion sociológica de la empresa, sino en una visión futurista debe normarse con un vocablo que permite una sinergia entre la concepción jurídica que tiene como finalidad lo lícito, la concepción económica que tiene como meta el beneficio y la concepción social que tiende a la satisfacción de las necesidades de un grupo social. Bajo esta perspectiva, nos preguntamos si nuestra legislación acorde con la legislación mundial debería seguir considerando el término empresa tendiendo como sus sujetos a los empresarios o considerar una noción distinta.

Ya en la visión presente, es decir, en la actualidad, a pesar de los cambios sustanciales descritos por la globalización, la transmisión de información y la especialización del trabajo sobre la lealtad laboral en la empresa, en nuestro país, sigue existiendo una mala práctica jurídica, al realizar una diferenciación de sociedad, empresa y comercio sólo de tipo normativo, entendiéndose a la persona natural con negocio que no constituyen una nueva persona jurídica como comerciante o empresa unipersonal, a la persona natural que de manera voluntaria y sin asociarse desea constituir una nueva persona jurídica para realizar actividad lucrativa como una empresa individual de responsabilidad limitadas y a la constitución por dos o más personas sean naturales o jurídicas como sociedades. Cabría entonces la pregunta ¿Cómo se denominan a los sujetos que realizan actividad en las tres formas descritas? El término sigue siendo empresario, por cuanto cualquiera de las formas descritas es una empresa por las características económicas que realiza. En consecuencia, existe un divorcio entre la economía y el Derecho en este aspecto. Francesco Galgano en su obra Diritto Commerciale - L'imprenditore -Le societá, edizione zanichelli, bologna 1998. quarta edizione. Ya se refiere a la sociedad unipersonal, lo señalo como referencia porque ya existen varios paises del mundo, que hace muchos años han superado el término empresa para negocios individuales, incluso en Colombia por dar un ejemplo en Sudamerica ya existe y por ello nuestro país no debería ser ajeno al cambio.

Por ello, citando pensamos que debe existir dos términos jurídicos en el futuro, claramente definidos uno para el ente y otro para sus miembros. En realidad, en la actualidad existen pero son términos confusos que suelen utilizarse de manera inadecuada.

Primero, partiremos que términos deberían ser proscritos para el futuro y luego señalaremos a nuestro parecer cual 
debería estar en el ordenamiento jurídico.

Sociedad: Término que no engloba la organización social, económica y jurídica que realiza actividad lucrativa porque esta actividad puede ser realizada por una o más personas.

Corporación: Utilizada sobretodo en el Derecho Anglosajón, este término se refería a las sociedades que cotizan en la Bolsa de Valores, es decir las sociedades anónimas abiertas. Existen diversos autores que consideran que las corporaciones son catalogadas por las personas como sociedades negativas, entre ellos:

Robert Keys, perteneciente a la Junta Canadiense de Comercio Internacional "CCIB" la equipara con agenda y la describe como algo malevolo y señala que el le gusta más los términos empresa, compañía y que el la llamaría comunidad empresarial.

Por su parte el profesor Joe Badaracco, quien enseña el curso de etica empresarial de la Universidad de Harvard, define: “La corporación es un grupo de individuos que trabajan juntos para la obtención de objetivos, siendo lo principal obtener beneficios, con el único límite que sean constantes, crecientes, sostenibles y legales"

Una opinión desde la optica social, muy importante la constituye la Premio Nobel, Vandana Shiva, siendo activista y lider ecologista, la define de la siguiente manera: “ La corporación no es una persona y no piensa, la gente que trabaja en ella piensa que para ellos es legítimo crear tecnología sui- cida, hoy en día los granjeros no pueden sembrar sus semillas porque estas semillas se destruyen a sí mismas mediante un gen suicida, estas semillas están diseñadas para producir cosecha una sola temporada, hay que tener verdaderamente una mente cruel, pensar así es incluso una guerra contra la evolución, pero está claro que los beneficios son para ellos, su prioridad.

Como podemos apreciar, los términos sociedad y corporación no se ajustan a la actualidad y como se dan los cambios, no es posible, que la percepción hacia ellos, mejore en el futuro.

Por ello, creo que es mejor seguir el Proyecto de José Manuel Calle Fiocco, uno de los más destacados propulsores de la LEY MARCO DEL EMPRESARIADO, para erradicar de manera definitiva el Código de Comercio que tiene más de 103 años.

Como bien se interpreta en esta interesante propuesta de futuro, en su exposición de motivos establece: "La LEY MARCO DEL EMPRESARIADO, que presentamos se sustenta en una base distinta a la asumida en la elaboración del Código de comercio de 1902. El nuevo eje de la vida económica es la empresa. Su tratamiento ha sido más propio del mundo de la economía o de la administración. El derecho la encuentra en la realidad y la trata en forma dispersa. Estimamos que ha llegado el momento que la legislación peruana, aluda en forma armónica y cohesionada a este centro de imputación fundamental en la economía moderna."
La empresa es definida como “ una organización económica destinada a la producción o comercialización de bienes o a la prestación de servicios".

"A lo largo de nuestro trabajo los integrantes de la Comisión hemos querido pensar genuinamente en la realidad empresarial peruana, caracterizada por la proliferación de unidades económicas pequeñas o medianas. Creemos que el gran capital no sólo es bienvenido sino necesario en un país sin ahorro interno suficiente y urgido de inversión de riesgo y de lenta recuperación. Empero, la vida económica de nuestro país y particularmente las posibilidades de empleo, se sustentan en el dinamismo de la pequeña y mediana empresa, en la que hemos fundamentalmente hemos pensado al concebir novedosas instituciones. Hemos creído también que la noción de empresa y actividad empresarial deben extenderse a todos los ámbitos de la vida económi$\mathrm{ca}$, incluyendo áreas en las que, hace algún tiempo la noción empresarial se rechazaba por prejuicios ideológicos. Hay que fomentar la actividad empresarial en el agro, en la artesanía, en la cultura, en el deporte. Sin perder la orientación humanista, la empresa ingresa también a la educación y a la salud. Toda reforma tiene una orientación valorativa y principista. Propugnamos un país en el que la empresa y el ímpetu empresarial sean asumidos como actitudes sociales."

Esta nueva concepción plasmada en el Proyecto Marco de la Ley del Empresariado, señala que cualquier persona sea na- 
tural o juridica puede hacer empresa no importando la finalidad lucrativa solo el intercambio de bienes o la prestación de servicios. Con lo cual, se busca deslindar de una manera definitiva la relación entre comercio y empresa, indicando que la empresa hace comercio y por ende tiene finalidad lucrativa. Ello, se ha hecho como señala la Comisión para romper la vieja concepción del Código Francés de 1807 que contemplaba los actos de comercio de manera objetiva, por la finalidad lucrativa.

Mención aparte, merece el acertado tratamiento que debe darse en un futuro sobre la persona que integra la empresa, denominada empresario, en ello se señala en el "Libro II del proyecto se regula al empresario como titular de la empresa. La ley admite que la titularidad corresponda a una persona natural o jurídica. En este último caso, adoptando la posición casi unánime de la doctrina se le otorga a la persona jurídica, como sujeto de derecho que es, la calidad de empresario.

Es importante poner énfasis en el distingo que la doctrina mercantil ha efectuado desde hace varias décadas entre empresario y empresa y específicamente entre sociedad y empresa. Si tuviéramos que partir de una explicación coloquial diríamos que la empresa es el negocio y el empresario el titular o quien lo conduce. Si A es dueño de una botica. La botica es la empresa y A es el empresario. Si ocurriera que $A$ es una sociedad, la regla es la misma: la botica es el negocio y A Sociedad Anónima es el empresario.

La empresa constituye un conjunto de "elementos" organizados. En tal virtud, es objeto de derecho y no sujeto de derecho. Es el empresario el que, en su condición de sujeto de derecho, crea, modifica, regula o extingue relaciones jurídicas. Lo que sí es evidente es que, en la actividad empresarial participan más sujetos de los que le dieron inicio, por ejemplo como accionistas al constituir la sociedad anónima titular de la empresa. Los trabajadores y la administración son parte de la empresa y no de la sociedad."

Bajo estas consideraciones, consideramos que, en el "fu- turo", la Legislación Peruana debería adoptar los términos de Empresa y Empresario, pero desde la concepción planteada en el Proyecto de Ley del Empresariado, ello con la finalidad de lograr una definición tridimensional social, económica y jurídica, entendida la económica no solo con el beneficio de sus miembros sino con el beneficio a los consumidores y usuarios.

En conclusión, no se trata de buscar una palabra nueva para regular la actividad empresarial en la Ley, sino remontarnos al pasado, ver el presente e imaginar el futuro acorde a la realidad para darle el verdadero sentido al término empresa y empresario.

Como señalaba Winston Churchill: "cuanto más atrás puedas mirar, más adelante verás"; y ello aplicado al Derecho, con instituciones tan antiguas como el propio ser humano, demuestra que varias leyes pueden perdurar en el tiempo siempre que se hayan concebido dentro de su real dimensión social. 